\title{
Tyrosine 394 Is Phosphorylated in Alzheimer's Paired Helical Filament Tau and in Fetal Tau with c-Abl as the Candidate Tyrosine Kinase
}

\author{
Pascal Derkinderen, ${ }^{1 *}$ Timothy M. E. Scales, ${ }^{1 \star}$ Diane P. Hanger, ${ }^{1}$ Kit-Yi Leung, ${ }^{2}$ Helen L. Byers, ${ }^{2}$ Malcolm A. Ward, ${ }^{2}$ \\ Christof Lenz, ${ }^{3}$ Caroline Price, ${ }^{4}$ Ian N. Bird, ${ }^{4}$ Timothy Perera, ${ }^{4}$ Stuart Kellie, ${ }^{4,5}$ Ritchie Williamson, ${ }^{1}$ Wendy Noble, ${ }^{1}$ \\ Richard A. Van Etten, ${ }^{6}$ Karelle Leroy, ${ }^{7}$ Jean-Pierre Brion, ${ }^{7}$ C. Hugh Reynolds, ${ }^{1}$ and Brian H. Anderton ${ }^{1}$ \\ ${ }^{1}$ Department of Neuroscience and ${ }^{2}$ Proteome Sciences plc, Institute of Psychiatry, King's College London, London SE5 8AF, United Kingdom, ${ }^{3}$ Mass \\ Spectrometry Laboratories, Applied Biosystems, 64293 Darmstadt, Germany, ${ }^{4}$ Yamanouchi Research Institute, Oxford OX4 4SX, United Kingdom, ${ }^{5}$ School \\ of Molecular and Microbial Sciences/Institute for Molecular Biosciences and Cooperative Research Centre for Chronic Inflammatory Diseases, University of \\ Queensland, Brisbane QLD4072, Australia, ${ }^{6}$ Molecular Oncology Research Institute, Tufts-New England Medical Center, Boston, Massachusetts 02111, and \\ ${ }^{7}$ Laboratory of Histology and Neuropathology, Université Libre de Bruxelles, School of Medicine, 1070 Brussels, Belgium
}

Tau is a major microtubule-associated protein of axons and is also the principal component of the paired helical filaments (PHFs) that comprise the neurofibrillary tangles found in Alzheimer's disease and other tauopathies. Besides phosphorylation of tau on serine and threonine residues in both normal tau and tau from neurofibrillary tangles, Tyr-18 was reported to be a site of phosphorylation by the Src-family kinase Fyn. We examined whether tyrosine residues other than Tyr-18 are phosphorylated in tau and whether other tyrosine kinases might phosphorylate tau. Using mass spectrometry, we positively identified phosphorylated Tyr-394 in PHF-tau from an Alzheimer brain and in human fetal brain tau. When wild-type human tau was transfected into fibroblasts or neuroblastoma cells, treatment with pervanadate caused tau to become phosphorylated on tyrosine by endogenous kinases. By replacing each of the five tyrosines in tau with phenylalanine, we identified Tyr-394 as the major site of tyrosine phosphorylation in tau. Tyrosine phosphorylation of tau was inhibited by PP2 (4-amino-5-(4-chlorophenyl-7-(t-butyl)pyrazolo[3,4-d]pyrimidine), which is known to inhibit Src-family kinases and c-Abl. Cotransfection of tau and kinases showed that Tyr-18 was the major site for Fyn phosphorylation, but Tyr-394 was the main residue for Abl. In vitro, Abl phosphorylated tau directly. Abl could be coprecipitated with tau and was present in pretangle neurons in brain sections from Alzheimer cases. These results show that phosphorylation of tau on Tyr-394 is a physiological event that is potentially part of a signal relay and suggest that Abl could have a pathogenic role in Alzheimer's disease.

Key words: Alzheimer's disease; Abl; tau; tyrosine phosphorylation; paired helical filaments; mass spectrometry

\section{Introduction}

Tau protein is predominantly expressed in axons, where it binds to and stabilizes microtubules (Buée et al., 2000), and is also the

Received Dec. 21, 2004; revised May 19, 2005; accepted May 19, 2005.

This work was supported by the Wellcome Trust, a Yamanouchi Research Institute studentship (T.M.E.S.), and grants from the Medical Research Council (MRC), the Alzheimer's Society, and the Belgian Fonds de la Recherche Scientifique Médicale and International Alzheimer Research Foundation. We thank I. M. Varndell and P. W. Sheppard (Biomol International, Exeter, UK) for many helpful discussions and suggestions, M. Goedert (MRC Laboratory of Molecular Biology, (ambridge, UK) and D. Markby (Sugen, San Francisco, CA) for supplying DNA constructs, P. Davies (Albert Einstein College of Medicine, Bronx, NY) for bringing to our attention that antibodies to Abl label degenerating neurons in the Alzheimer's diseased brain, and the MRC Brain Bank at the Institute of Psychiatry for brain tissue.

*P.D. and T.M.E.S. contributed equally to this work.

Correspondence should be addressed to Dr. C. H. Reynolds, Department of Neuroscience, Institute of Psychiatry, Box 037, King's College London, De Crespigny Park, Denmark Hill, London SE5 8AF, UK. E-mail: h.reynolds@iop.kcl.ac.uk.

P. Derkinderen's present address: Neurology Department and Institut National de la Santé et de la Recherche Médicale U643, Centre Hospitalier Universitaire de Nantes, 44093 Nantes Cedex 1, France.

C. Price's present address: Current Medicine Group, Porters South, 4 Crinan Street, London N1 9XW, UK.

I. N. Bird's present address: Celltech R\&D, 216 Bath Road, Slough, Berkshire SL1 4EN, UK.

T.Perera's present address: Johnson and Johnson Pharmaceutical Research and Development, Turnhoutsweg 30, B-2340 Beerse, Belgium.

DOI:10.1523/JNEUROSCI.1487-05.2005

Copyright $\odot 2005$ Society for Neuroscience $\quad$ 0270-6474/05/256584-10\$15.00/0 main component of paired helical filaments (PHFs). PHFs form neurofibrillary tangles (NFTs) that are a pathological feature of Alzheimer's disease (AD) (Smith and Anderton, 1994; Buée et al., 2000) and several other "tauopathies" (Spillantini and Goedert, 1998; Delacourte and Buée, 2000). These include frontotemporal dementia with parkinsonism linked to chromosome 17, the patients of which have mutations in the tau gene itself (Hutton et al., 1998; Poorkaj et al., 1998), suggesting that tau has an important role in these neurodegenerative diseases, including AD.

Phosphorylation on at least 25 serine and threonine residues has been reported in tau isolated from an Alzheimer brain (Morishima-Kawashima et al., 1995; Hanger et al., 1998; Anderton et al., 2001). Tau hyperphosphorylation hinders its ability to bind to microtubules (Biernat et al., 1993). Tau in PHF (PHFtau) is abnormally hyperphosphorylated, and it is hypothesized that this hyperphosphorylation contributes to neurodegeneration through the destabilization of microtubules. Several candidate kinases have been identified that can phosphorylate tau on sites found to be phosphorylated in PHF-tau (Lovestone and Reynolds, 1997). These include cyclin-dependent kinase 5 (cdk5) (Maccioni et al., 2001) and glycogen synthase kinase-3 (Anderton 
et al., 2001). Recent studies with transgenic animals further support a key role for cdk5 (Noble et al., 2003) and glycogen synthase kinase-3 (Spittaels et al., 2000; Lucas et al., 2001) in the formation of NFTs.

There is now evidence that phosphorylation of tau on tyrosine residues may also occur. Human tau has five tyrosines $(18,29$, 197, 310, and 394; numbered according to the sequence of the longest CNS isoform), and phosphorylation by the kinase Fyn has been demonstrated in cell models (Lee et al., 1998). We have shown previously that PHF-tau from some AD cases contains tyrosine-phosphorylated tau, and that treatment of cultured neurons with amyloid- $\beta$ peptide $(\mathrm{A} \beta)$ induced tyrosine phosphorylation of several proteins, including tau (Williamson et al., 2002). Using cotransfection to express Fyn along with deletion fragments of tau, a recent study showed that Tyr-18 was one of the tyrosine residues phosphorylated by Fyn in COS-7 cells (Lee et al., 2004). Moreover, immunocytochemical studies indicated that tau phosphorylated on Tyr-18 was present in NFTs in the AD brain (Lee et al., 2004). Using mass spectrometry, however, we identified phosphorylated Tyr-394 in both PHF-tau and in tau from a fetal brain. We used the tyrosine phosphatase inhibitor pervanadate in tau-transfected cells and found that Tyr-394 is the main tyrosine phosphorylated on tau in these cells. In cotransfected cells, Fyn phosphorylated predominantly Tyr-18, but c-Abl phosphorylated tau predominantly on Tyr-394. Recently, $\mathrm{A} \beta$ has been shown to activate $\mathrm{Abl}$ in hippocampal neurons ( $\mathrm{Al}$ varez et al., 2004), and we report elevated Abl in pretangle neurons in $\mathrm{AD}$. Therefore, our findings suggest that $\mathrm{Abl}$ mediates the $\mathrm{A} \beta$-induced increase in tau tyrosine phosphorylation (Williamson et al., 2002) and opens new insights into the physiological function of tau and into its role in neurodegenerative disorders.

\section{Materials and Methods}

Preparation of human tau. The frozen cortex from an AD brain was supplied by the Medical Research Council Neurodegenerative Diseases Brain Bank, and PHF-tau was purified by Mono Q chromatography and reversed-phase HPLC as described previously (Hanger et al., 1998).

Brain tissue from an 18-week-old fetus was removed and placed in Hanks' buffered saline solution for $\sim 1 \mathrm{~h}$ at $4^{\circ} \mathrm{C}$ and then frozen in liquid nitrogen and stored at $-70^{\circ} \mathrm{C}$. Tissue was thawed and homogenized in ice-cold 2-( $N$-morpholino) ethanesulfonic acid (Mes; $100 \mathrm{~mm}$ ), pH 6.5, containing $0.5 \mathrm{~mm} \mathrm{MgCl}, 1 \mathrm{~mm}$ EGTA, $1 \mathrm{M} \mathrm{NaCl}, 50 \mathrm{~mm} \mathrm{~N}$-acetyl glucosamine, $20 \mathrm{~mm} \mathrm{NaF}, 10 \mathrm{~mm}$ Na pyrophosphate, $50 \mathrm{~mm}$ imidazole, 25 mM $\beta$-glycerol phosphate, $2 \mathrm{~mm}$ dithiothreitol, $5 \mu \mathrm{m}$ okadaic acid, and 1 mM phenylmethanesulfonyl fluoride using $\sim 1 \mathrm{ml}$ of buffer/g tissue. The homogenate was centrifuged at $100,000 \times g_{(a v)}$ for $1 \mathrm{~h}$ at $4^{\circ} \mathrm{C}$. The supernatant was heated at $100^{\circ} \mathrm{C}$ for $10 \mathrm{~min}$, cooled for $10 \mathrm{~min}$ in ice, and centrifuged at $100,000 \times g_{(\text {av) }}$ for $30 \mathrm{~min}$ at $4^{\circ} \mathrm{C}$. Heat-stable proteins in the supernatant were precipitated using $45 \%$ saturated ammonium sulfate. The pellet was redissolved in $100 \mathrm{~mm}$ Mes buffer as above but without $\mathrm{NaCl}$, and perchloric acid was added to a final concentration of $2.5 \%$ $(\mathrm{w} / \mathrm{w})$. The supernatant containing acid-soluble proteins was dialyzed into $50 \mathrm{~mm}$ ammonium bicarbonate, centrifuged to remove insoluble material, and stored at $-70^{\circ} \mathrm{C}$.

Tau cDNA constructs. A construct of human tau 2N4R (longest brain isoform) was donated by M. Goedert (Medical Research Council Laboratory of Molecular Biology, Cambridge, UK). Recombinant tau 2N4R was expressed in Escherichia coli BL21 (DE3) and purified as described previously (Mulot et al., 1994).

For expression in mammalian cells, the cDNA coding for wild-type tau 2N4R was subcloned into the pcDNA3.1/V5-His-TOPO vector (Invitrogen, Paisley, UK), yielding a construct with C-terminal V5 and His tags. To generate the five tau constructs, each with a single tyrosine replaced by phenylalanine, a QuikChange XL site-directed mutagenesis kit (Stratagene, Amsterdam, The Netherlands) was used. Primers were as follows: to convert Tyr-18 to Phe (giving tau construct Y18F), forward primer
5'-CAC GCT GGG ACG TTC GGG TTG GGG GAC-3' (Primer A) and reverse primer 5' -GTC CCC CAA CCC GAA CGT CCC AGC GTG-3'; to convert Tyr-29 to Phe (giving Y29F), forward primer 5' -GAT CAG GGG GGC TTC ACC ATG CAC CAA G-3' (Primer B) and reverse primer 5' -C TTG GTG CAT GGT GAA GCC CCC CTG ATC-3'; to convert Tyr-197 to Phe (giving Y197F), 5'-GAT CGC AGC GGC TTC AGC AGC CCC GG-3' (Primer C) and reverse primer 5' -CC GGG GCT GCT GAA GCC GCT GCG ATC-3'; to convert Tyr-310 to Phe (giving Y310F), forward primer 5'-GGC AGT GTG CAA ATA GTC TTC AAA CCA GTT GAC CTG AG-3' (Primer D) and reverse primer 5' -CT CAG GTC AAC TGG TTT GAA GAC TAT TTG CAC ACT GCC-3'; and to convert Tyr-394 to Phe (giving Y394F), forward primer 5'-GCG GAG ATC GTG TTC AAG TCG CCA GTG G-3' (Primer E) and reverse primer 5'-C CAC TGG CGA CTT GAA CAC GAT CTC CGC-3'. The sequence of the full insert was determined for each construct.

To change all five tyrosines to phenylalanines, a QuikChange multisite-directed mutagenesis kit (Stratagene) was used, with the five primers A to $\mathrm{E}$ (see above). Plasmids were sequenced, and in addition to identifying constructs in which all five tyrosines had been replaced by phenylalanine (TauYallF), constructs with a single tyrosine remaining were produced that contained four phenylalanines and only Tyr-18, Tyr29 , or Tyr-197. Mutants containing only Tyr-310 or only Tyr-394 were generated from the TauYallF construct by single site-directed mutagenesis as above using the following primers: for Tyr-310only, forward primer 5'-GGC AGT GTG CAA ATA GTC TAC AAA CCA GTT GAC CTG AG-3' and reverse primer $5^{\prime}$-CT CAG GTC AAC TGG TTT GTA GAC TAT TTG CAC ACT GCC-3'; and for Tyr-394only, forward primer 5'-GCG GAG ATC GTG TAC AAG TCG CCA GTG G-3' and reverse primer 5'-C CAC TGG CGA CTT GTA CAC GAT CTC CGC-3'. The five constructs with one remaining tyrosine were termed Y18only, Y29only, etc, and their tau-coding sequences were verified by sequencing.

Other cDNA constructs. Fyn cDNA was a gift from D. Markby (Sugen, San Francisco, CA), Src cDNA was obtained from Upstate Ltd (Src cDNA allelic pack; Upstate Ltd, Milton Keynes, UK), and c-Abl and c-Abl $\Delta \mathrm{XB}$ cDNA [a constitutively active form of c-Abl, with deletion of most of the Src homology 3 (SH3) domain] have been described previously (Jackson and Baltimore, 1989; Daley et al., 1992).

Antibodies and other materials. Monoclonal anti-V5 antibody was from Invitrogen (Paisley, UK). Monoclonal antibodies to phosphotyrosine (4G10 and P-Tyr-100) were obtained from Upstate Ltd and from Cell Signaling Technology (Hitchin, UK), respectively. The TP70 polyclonal antibody to tau has been described previously (Brion et al., 1993). The following commercially available phosphospecific antibodies were used: polyclonal antibody to the autophosphorylated form of Src-family kinases (Phospho-Src family, Tyr 416; Cell Signaling Technology), polyclonal antibody to the phosphorylated form of $\mathrm{c}-\mathrm{Abl}\left(\mathrm{pY}^{412}\right.$; Biosource, Nivelles, Belgium), and AT8 monoclonal to phosphorylated tau (pSer202/pThr205; Innogenetics, Gent, Belgium). Polyclonal antibody to Src-family kinases (SRC-2) and monoclonal (s.c.-23) and polyclonal (K-12) antibodies to c-Abl were obtained from Santa Cruz Biotechnology (Santa Cruz, CA). 4-Amino-5-(4-chlorophenyl-7(t-butyl)pyrazolo[3,4-d]pyrimidine (PP2), 4-amino-7-phenylpyrazol [3,4-d]pyrimidine (PP3), sodium orthovanadate, and Tween 20 were obtained from Calbiochem (La Jolla, CA) (Merck Biosciences, Nottingham, UK), protein-G Sepharose 4 fast flow was obtained from Amersham Biosciences (Chalfont St. Giles, UK), and Nonidet P-40 (NP-40), hydrogen peroxide, and catalase were obtained from Sigma-Aldrich (Poole, UK).

Vanadate stock solution was prepared as a $200 \mathrm{~mm}$ solution of sodium orthovanadate and was adjusted to $\mathrm{pH} 10.0$ and heated until the solution turned colorless. The $\mathrm{pH}$ was then readjusted to 10.0 , and the previous steps were repeated until the solution remained colorless and the $\mathrm{pH}$ was stabilized at 10.0. Sodium orthovanadate was then stored as aliquots at $-20^{\circ} \mathrm{C}$ (Gordon, 1991). Pervanadate was prepared as a $100 \times$ stock by adding $50 \mu \mathrm{l}$ of $200 \mathrm{~mm}$ sodium orthovanadate and $1.6 \mu \mathrm{l}$ of $30 \%(\mathrm{w} / \mathrm{w})$ hydrogen peroxide to $948 \mu \mathrm{l}$ of water for $5 \mathrm{~min}$ at room temperature, giving $10 \mathrm{~mm}$ sodium orthovanadate and $16.3 \mathrm{~mm}$ hydrogen peroxide. After $5 \mathrm{~min}$ at room temperature, the excess hydrogen peroxide was 
removed by adding $200 \mu \mathrm{g} / \mathrm{ml}$ catalase ( $\sim 520 \mathrm{U} / \mathrm{ml}$ ) and incubating for an additional 5 min (Huyer et al., 1997).

Mass spectrometry. Tau from PHF and human fetal tau were resolved by one-dimensional SDS-PAGE and stained with Brilliant Blue G colloidal concentrate (Sigma). The bands corresponding to tau were excised, reduced, alkylated, and digested with either trypsin or Asp-N (Betts et al., 1997; Shevchenko et al., 2002). Tau peptides were extracted from the gel pieces with two wash cycles of $50 \mathrm{~mm}$ ammonium bicarbonate and acetonitrile. The extract was pooled with the initial supernatant, lyophilized, and resuspended in 20-25 $\mu \mathrm{l}$ of $50 \mathrm{~mm}$ ammonium bicarbonate.

Peptide digests were analyzed by on-line liquid chromatography tandem mass spectrometry (LC/MS/MS). Chromatographic separations were performed using an Ultimate LC system (Dionex, Camberley, UK). Peptides were resolved by reversed-phase chromatography on a $75 \mu \mathrm{m}$ (inner diameter) C18 PepMap column. A gradient of acetonitrile in $0.05 \%$ formic acid was delivered over $60 \mathrm{~min}$ to elute the peptides at a flow rate of $200 \mathrm{nl} / \mathrm{min}$. Peptides were ionized by electrospray ionization using a Z-spray source fitted to a QTof-micro (Waters Ltd, Elstree, UK). The instrument was set to run in automated switching mode, selecting precursor ions based on their intensity and charge state, for sequencing by collision-induced fragmentation. The MS/MS analyses were conducted using collision energy profiles that were chosen based on the mass/charge $(\mathrm{m} / \mathrm{z})$ and the charge state of the peptide and optimized for phosphorylated peptides.

The mass spectral data were processed into peak lists containing the $\mathrm{m} / \mathrm{z}$ value of each precursor ion, its charge state, and the corresponding fragment ion $\mathrm{m} / \mathrm{z}$ values and intensities. The data were searched against a custom-built database containing the different isoforms of tau using the Mascot searching algorithm (Matrix Science, Oxford, UK). Peptides and phosphopeptides of tau were identified based on the search criteria set (i.e., the cleavage enzyme used with up to three missed cleavages, carbamidomethyl modification of cysteine residues, and oxidized methionine). Phosphorylated peptides were identified by selecting for tyrosine and serine/threonine phosphorylation as a variable modification. The exact location of phosphorylation within each peptide was determined by the pattern of fragment ions produced (b series and y series, from the $\mathrm{N}$ and C termini, respectively) (Roepstorff and Fohlman, 1984); this typically involved visual verification of individual MS/MS spectra.

For PHF-tau, additional supporting evidence was obtained for the phosphorylation of Tyr-394 using the 4000QTRAP mass spectrometer (Applied Biosystems, Darmstadt, Germany), interfaced to an Ultimate LC system with the chromatography performed as described above. Chromatographic separation of two distinct forms of the doubly phosphorylated peptide TDHGAEIVPYKSPVVSGDTpSPR and TDHGAEIVYKpSPVVSGDTpSPR was achieved, and separate enhanced product ion (EPI) spectra were recorded for each phosphopeptide. The MS/MS fragment ions clearly defined the sites of phosphorylation in each case.

Cell culture, transfection, and immunoprecipitation. COS-7 cells were cultured in DMEM supplemented with $10 \%$ (v/v) fetal calf serum, 2 mM L-glutamine, $10 \mathrm{U} / \mathrm{ml}$ penicillin, and $10 \mu \mathrm{g} / \mathrm{ml}$ streptomycin. cDNA vectors were introduced into COS-7 cells by lipofectamine transfection. Cells were transfected at $90 \%$ confluency with $8.6 \mu \mathrm{g}$ of DNA and $15 \mu \mathrm{l}$ of lipofectamine per $60 \mathrm{~mm}$ dish in Optimem (Invitrogen) for $5 \mathrm{~h}$. Human neuroblastoma SHSY5Y cells were cultured in DMEM F-12 medium with $15 \%(\mathrm{v} / \mathrm{v})$ fetal calf serum, with glutamine and antibiotics as for COS-7 cells. Cells were transfected at $60-70 \%$ confluency as for COS-7 cells, except that lipofectamine was replaced with $10 \mu \mathrm{l}$ of lipofectamine2000. For cotransfection experiments, Chinese hamster ovary (CHO) cells were cultured in F-12 nutrient mixture with $10 \%(\mathrm{v} / \mathrm{v})$ fetal calf serum, $10 \mathrm{U} / \mathrm{ml}$ penicillin, and $10 \mu \mathrm{g} / \mathrm{ml}$ streptomycin. Cells were transfected at $70 \%$ confluency with the same protocol used for COS-7 cells.

Transiently transfected cells were harvested in NETF buffer $(100 \mathrm{~mm}$ $\mathrm{NaCl}, 2$ mM EGTA, $50 \mathrm{~mm}$ Tris-Cl, pH 7.4, and $50 \mathrm{~mm} \mathrm{NaF}$ ) containing $1 \%(\mathrm{v} / \mathrm{v})$ NP-40, $2 \mathrm{~mm}$ orthovanadate, and protease inhibitors (Complete; Roche Molecular Biochemicals, Lewes, UK). Samples were precleared with $40 \mu$ l of protein-G Sepharose beads (which had been washed in NETF buffer to give a $50 \%$ slurry), and immunoprecipitations were performed with monoclonal anti-V5 antibody preadsorbed onto
protein-G Sepharose beads. The protein-G Sepharose-bound immune complexes were washed twice in NETF buffer containing $2 \mathrm{~mm}$ orthovanadate and NP-40 (1\% w/v) and once in NETF without detergent. Pellets from the immunoprecipitations were heated at $95^{\circ} \mathrm{C}$ for $5 \mathrm{~min}$ in $70 \mu \mathrm{l}$ of SDS-PAGE sample buffer (Laemmli, 1970) for SDS-PAGE.

Western blot analysis. Denaturing gel electrophoresis was performed as described previously (Derkinderen and Girault, 1997; Williamson et al., 2002) using 8 or $10 \%(\mathrm{w} / \mathrm{v})$ polyacrylamide gels. Blots were visualized using enhanced chemiluminescence detection (Amersham Biosciences). Quantification was achieved by scanning the developed films with a GS710 Calibrated Imaging Densitometer (Bio-Rad, Hemel Hempstead, UK) and measuring relative optical density with Quantity One 4.0.3 software (Bio-Rad). Phosphotyrosine immunoreactivities with 4G10 were normalized for tau concentration using TP70 antibody and expressed as a percentage of the values obtained for the wild-type construct (WT) ( \pm SEM). Graph Pad Prism 4.0 software was used for statistical analysis.

In vitro phosphorylation of tau. Recombinant human tau $(1 \mu \mathrm{g})$ was incubated with or without $0.5 \mu \mathrm{g}$ of c-Abl (Upstate Ltd) in $30 \mu$ l of kinase buffer (50 mM HEPES, pH 7.4, $10 \mathrm{~mm} \mathrm{MnCl}_{2}$ ) in the presence of $1 \mathrm{~mm}$ ATP for $30 \mathrm{~min}$ at $30^{\circ} \mathrm{C}$. SDS-PAGE sample buffer $(30 \mu \mathrm{l})$ was added to stop the reaction. Control tau was put through the same procedure but without kinase.

Immunocytochemistry. Human tissue samples were obtained from autopsy material following approval of the Ethic Committee of the School of Medicine of the Free University of Brussels. Tissue blocks of the hippocampus and the parahippocampal gyrus in two control subjects ( 81 and 86 years of age) and in two patients with Alzheimer's disease ( 84 and 91 years of age) were fixed by immersion in $10 \%(\mathrm{v} / \mathrm{v})$ formalin for 3 weeks. Tissue samples were embedded in paraffin and cut in tissue sections with a thickness of $10 \mu \mathrm{m}$. The Alzheimer's disease patients fulfilled the neuropathological criteria for stages V-VI according to the Braak nomenclature.

Double immunocytochemical labeling was performed as reported previously (Leroy et al., 2002). Briefly, tissue slides were incubated sequentially with $10 \%(\mathrm{v} / \mathrm{v})$ normal goat serum in TBS (10 mм Tris- $\mathrm{HCl}$, $\mathrm{pH} 7.4 / 0.15 \mathrm{M} \mathrm{NaCl}$ ) for $1 \mathrm{~h}$ and with the $\mathrm{K}-12 \mathrm{c}$-Abl polyclonal and the AT8 monoclonal antibodies [diluted $1 / 1000$ and $1 / 100$, respectively, in TBS containing $1 \%(\mathrm{v} / \mathrm{v})$ normal goat serum] overnight. The c-Abl antibody was detected by a goat anti-rabbit antibody conjugated to biotin (Vector Laboratories, Burlingame, CA), followed by streptavidin conjugated to peroxidase and incubation with Alexa 488-tyramide (Molecular Probes, Eugene, OR); the AT8 antibody was detected by a goat antimouse antibody conjugated to Alexa 594 (Molecular Probes). The sections were then treated with $4^{\prime}, 6^{\prime}$-diamidino-2-phenylindole (DAPI) for nuclear staining. Tissue sections were examined under UV illumination with a Zeiss (Welwyn Garden City, UK) Axioplan microscope, and digital images were acquired using an Axiocam HRc camera.

\section{Results}

\section{Tyrosine 394 is phosphorylated in PHF tau and in tau from} human fetal brain

Paired helical filament tau is known to be hyperphosphorylated on numerous sites. Most of the sites reported to date have involved serine or threonine, but a recent report identified phosphorylation of Tyr-18 using antibodies (Lee et al., 2004). PHF tau was digested with trypsin, and the peptides were analyzed by LC/MS/MS using the QTof-micro mass spectrometer. A doubly charged precursor ion of $\mathrm{m} / \mathrm{z} 1188$ containing residues 386-406 was generally found to give weak fragment ions of m/z 1194 and 1211; these could represent the b10 ion and y12-98 ion, respectively (i.e., y12 with loss of $98 \mathrm{Da}$ as phosphate), derived from the doubly phosphorylated peptide sequence TDHGAEIVPYKSPVVSGDTpSPR with phosphates attached at residues 9 and 19 (Tyr394 and Ser-404 of tau, the latter as dehydroalanine). These ions with $\mathrm{m} / \mathrm{z} 1194$ and 1211 discriminate between phosphorylation of residue 9 of the peptide (Tyr-394) and phosphorylation on 
A

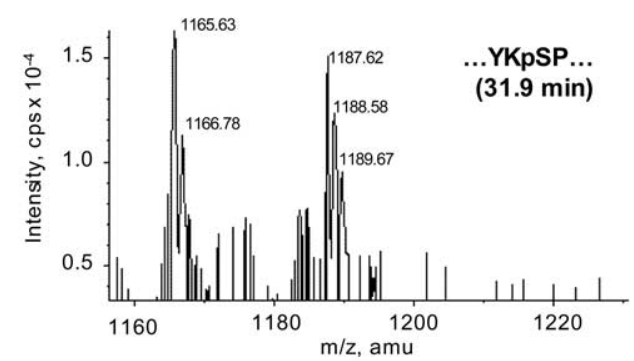

B

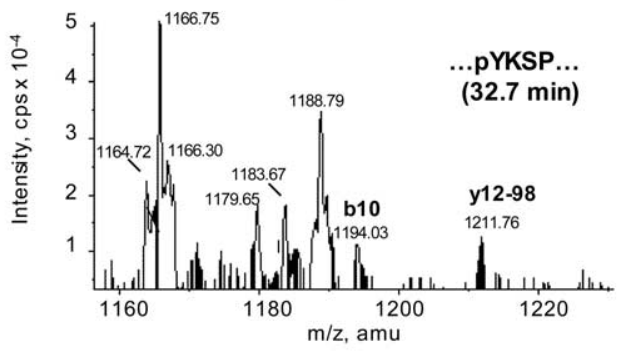

C

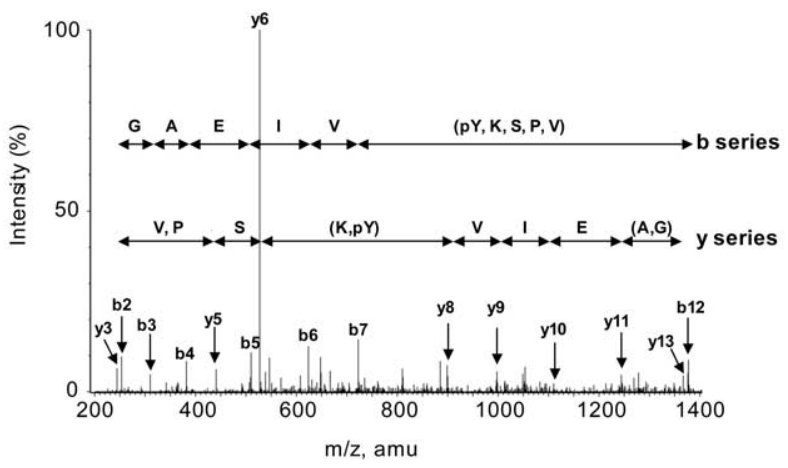

Figure 1. Mass spectrometric identification of phosphorylated tyrosine 394 in tau from PHF and in fetal tau by mass spectrometry. A, PHF tau was isolated from Alzheimer brain tissue and digested with trypsin for analysis by LC/MS/MS. The mass/charge ratio is plotted against intensity. Part of the EPI spectrum is shown of the doubly charged precursor peptide of $\mathrm{m} / \mathrm{z} 1188.3$ eluting at $31.9 \mathrm{~min}$, TDHGAEIVYKpSPVVSGDTPSPR (tau residues $386-406$ ). $\boldsymbol{B}$, As in $\boldsymbol{A}$ but eluting at $32.7 \mathrm{~min}$. The peak ions of $\mathrm{m} / \mathrm{z} 1194$ (b10) and 1211 (y12-98), which are not present in $\boldsymbol{A}$, show that the precursor peptide is TDHGAEIVpYKSPVVSGDTPSPR [i.e., it is phosphorylated on residue 9 (Tyr-394) and not on residue 11 (Ser-396)]. The nomenclature is as described by Roepstorff and Fohlman (1984). C, Tau from human fetal brain tissue was isolated and purified by gel electrophoresis, digested with Asp-N, and analyzed by LC/MS/MS. The fragmentation spectrum is shown for the peptide DHGAEIV YKSPVV $S$ SG (tau residues 387-401). The y ion series demonstrates that Tyr-394 is phosphorylated (ions of the $\mathrm{m} / \mathrm{z}$ of $\mathrm{y} 8$ and above contain phosphate, whereas y 6 and below do not), and that Ser- 400 is dehydroalanine (mass 69 in all identified y ions) caused by loss of phosphate in the fragmentation reaction, whereas Ser-396 is intact nonphosphorylated serine.

residue 11 (Ser-396). However, using the automated switching mode of the QTof-micro mass spectrometer, the MS/MS spectra obtained were typically heterogeneous and contained fragment ions that also indicated the presence of another distinct phosphopeptide, TDHGAEIVYKpSPVVSGDTpSPR, with phosphates attached at residues 11 and 19 (Ser-396 and Ser-404 of tau). These two peptides have the same molecular mass and amino acid sequence and the same number of phosphate groups, but these are attached to different amino acids within the peptide. Therefore, both forms give rise to precursor ions of the same $\mathrm{m} / \mathrm{z}$, and in this case, although they are resolved chromatographically, there are no distinct MS/MS spectra. To confirm phosphorylation of Tyr-394, the novel MS/MS scan functions of the 4000QTRAP were exploited. The $\mathrm{m} / \mathrm{z} 1188$ precursor ion gave

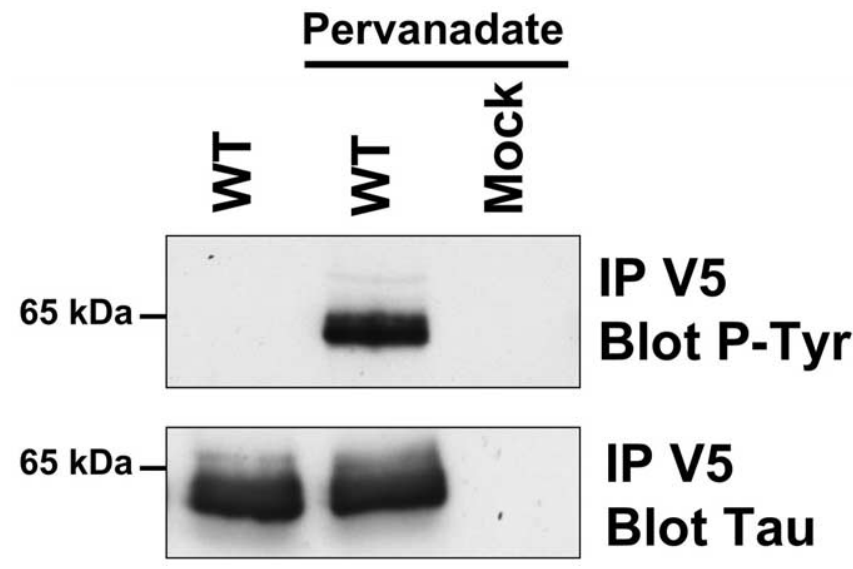

Figure 2. Tau is phosphorylated on tyrosine in pervanadate-treated COS-7 cells. COS-7 cells were transiently transfected with either empty vector (mock; right lane) or V5-tagged tau (WT; center lane) and treated for $20 \mathrm{~min}$ with pervanadate ( $100 \mu \mathrm{m}$ sodium orthovanadate and $4 \mathrm{~mm}$ $\mathrm{H}_{2} \mathrm{O}_{2}$ and catalase). As a control, cells transfected with V5-tagged tau (2N4R; left lane) were treated with hydrogen peroxide and catalase but without sodium orthovanadate. Immunoblots were performed on duplicate membranes using 4G10 antiphosphotyrosine antibody (IP V5, Blot P-Tyr) or anti-tau TP70 antibody (IP V5, Blot Tau).

two distinct EPI spectra, eluting at $31.9 \mathrm{~min}$ (Fig. $1 \mathrm{~A}$ ) and 32.7 min (Fig. $1 B$ ); only the latter yielded the fragments of $\mathrm{m} / \mathrm{z} 1194$ (b10) and 1211 (y12-98) that are diagnostic of pTyr-394 in this peptide. This confirms that phosphorylated Tyr-394 was present in PHF tau.

In analogous experiments using Asp-N digests of tau from human fetal brain, the peptides were analyzed by LC/MS/MS using the QTof-micro mass spectrometer. One was identified as containing residues 387-401 of tau with two phosphate groups; its fragmentation spectrum is shown in Figure 1C. The fragment ions show unequivocally that phosphate was present on Tyr-394, whereas Ser-396 was unphosphorylated. It was deduced that Ser-400 was the site of the second phosphate, identified here as dehydroalanine. Therefore, the sequence of the peptide is DHGAEIV $\mathrm{PKSPVV}_{\mathrm{P}} \mathrm{SG}$.

These results show that phosphorylation of tau on Tyr-394 may be a normal physiological event and also that it could be involved in the pathological process leading to tau aggregation. We therefore wanted to determine whether normal cells contain endogenous kinases that can phosphorylate tau on tyrosine and, if so, on which sites.

\section{Tau is primarily phosphorylated on Tyr-394 in} pervanadate-treated cells

To induce tyrosine phosphorylation of tau in transfected COS-7 and SHSY5Y cells, we used the protein-tyrosine phosphatase inhibitor pervanadate. Pervanadate is a cell-permeant inhibitor of protein-tyrosine phosphatases that acts by irreversible oxidation of the catalytic site of these enzymes (Huyer et al., 1997). Cells expressing wild-type tau (V5-tagged) were treated with pervanadate $(100 \mu \mathrm{M}$ for $20 \mathrm{~min}$ ), or control-treated (see Materials and Methods) were lysed, and the tau was immunoprecipitated with anti-V5 antibody. The extracts were analyzed in duplicate by Western blotting with antibodies to phosphotyrosine (4G10) or tau (TP70). As shown in Figure 2, tau is phosphorylated in response to pervanadate, whereas treatment of cells with hydrogen peroxide and catalase results in no change in tyrosine phosphorylation of tau.

To map the phosphorylated tyrosine residues, constructs of tau with one tyrosine changed to phenylalanine (Y18F, Y29F, 
Y197F, Y310F, and Y394F) were transfected into COS-7 cells and treated with pervanadate. Western blot analysis showed that the Y394F mutation is the only single-tyrosine mutation that resulted in a significant effect, reducing phosphotyrosine immunoreactivity to $\sim 10 \%$ of the wild-type control (Fig. $3 A, B)$. This suggests that most, but not all, of the endogenous tyrosine phosphorylation of tau in COS-7 cells occurs on Tyr394. Similar results were obtained using P-Tyr-100 antiphosphotyrosine antibody (data not shown). Tyrosine phosphorylation of the Y18F, Y29F, Y197F, and Y310F constructs was not significantly different from the wild-type control. For the Y197F mutant construct, however, a modest decrease in tyrosine phosphorylation was observed in some experiments.

To confirm these results, we transfected each of five other tau mutants in which only one tyrosine residue remained, with the other four replaced by phenylalanine, into COS-7 cells and treated them for 20 min with pervanadate. Analysis using phosphotyrosine antibodies showed that little or no tyrosine phosphorylation could be detected after treatment with pervanadate in cells expressing Y18only, Y29only, Y197only, or Y310only, whereas pervanadate induced an increase in phosphotyrosine staining of Y394only, similar to that observed with wildtype tau (Fig. 3C,D). Together, these results show that, in pervanadate-treated COS-7 cells, phosphorylation occurs mainly on Tyr-394, with a little phosphorylation on other tyrosine residues in tau.

To determine whether Tyr-394 is also the principal site of tyrosine phosphorylation on tau in cells of neuronal origin, SHSY5Y neuroblastoma cells were transiently transfected with V5-tagged wild-type or Y394F tau constructs. After pervanadate treatment, the wild-type tau, but not the Y394F mutant, showed substantial tyrosine phosphorylation (Fig. 3E). This suggests that the endogenous tyrosine kinases in neuronal SHSY5Y cells, as in fibroblasts, preferentially phosphorylate tau on Tyr-394.

\section{Both Src-family kinases and c-Abl bind to and phosphorylate tau}

To elucidate which protein tyrosine kinases might be involved in the tyrosine phosphorylation of tau in cells observed with pervanadate, we used PP2, an inhibitor of Src-family kinases, and its counterpart, PP3, a related compound that inhibits epidermal growth factor receptor activation but not Src-family kinases (Hanke et al., 1996). Western blot analysis using SRC-2 antibody revealed that COS-7 cells express Src-family kinase members (data not shown). Wild-type tau was transfected into COS-7 cells and pretreated with $10 \mu \mathrm{M}$ PP2, PP3, or DMSO-vehicle control for $1 \mathrm{~h}$ before treatment with pervanadate. Pretreatment of cells with PP2 strongly decreased the tyrosine phosphorylation of tau induced by pervanadate, whereas PP3 did not (Fig. 4). These results suggest that Src-family or other related kinases are involved in tau tyrosine phosphorylation.

To determine more directly whether Src-family members can

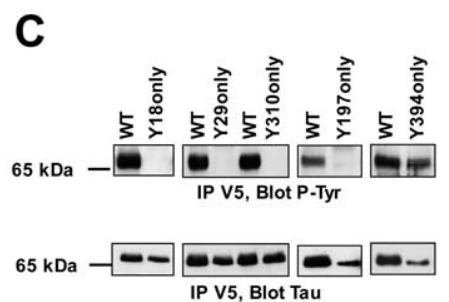

D

$\mathbf{E}$

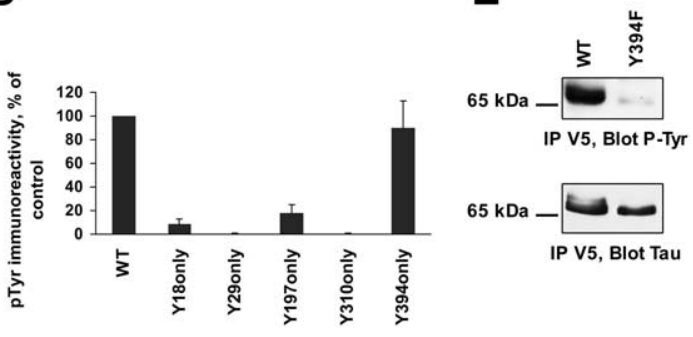

Tau is phosphorylated on tyrosine 394 in pervanadate-treated COS-7 cells. A, COS-7 cells were transiently transfected -tagged constructs expressing human tau (2N4R, WT) or with mutants of tau in which one tyrosine had been replaced by

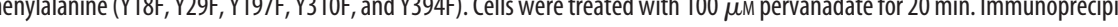
列 one tyrosine remaining (Y18only, Y29only, Y197only, Y310only, or Y394only). Cells were treated with pervanadate for 20 min $D$ Immunoreactivity for each Yonly construct with $4 \mathrm{G} 10$ was quantified as described above in three separate experiments. The e-sample $t$ test was used for statistical evaluations. Y394F was the only construct resulting in a statistically significant decrease in tau phosphorylation compared with the WT construct $(p<0.0001)$. E, SHSY5Y cells were transfected with V5-tagged wildtype or Y394F-tau and treated and analyzed as in $\boldsymbol{A}$.

phosphorylate tau in cells, cotransfection experiments were performed in $\mathrm{CHO}$ cells using c-Src or Fyn expression vectors along with the wild-type tau construct without pervanadate treatment. $\mathrm{CHO}$ cells were used in these double-transfection experiments. Western blot analysis was then performed on immunoprecipitated tau using the anti-phosphotyrosine (4G10) and anti-tau (TP70) antibodies and on total cell lysates using SRC-2 antibody. As illustrated in Figure 5, cotransfection of c-Src or Fyn with tau results in increased tyrosine phosphorylation of tau in $\mathrm{CHO}$ cells. The phosphotyrosine immunoreactivity of tau was weaker in all experiments performed with Fyn compared with those with c-Src (Fig. 5A). When Fyn or c-Src were cotransfected with tau, tau immunoprecipitates contained a $\sim 60 \mathrm{kDa}$ band that migrated between the immunoglobulin heavy chains and tau. The $60 \mathrm{kDa}$ band is likely to contain Src or Fyn, because these enzymes are tyrosine phosphorylated and are known to interact with tau through their SH3 domains(Lee et al., 1998). The presence of Src-family kinases in the $60 \mathrm{kDa}$ band was confirmed by blotting with SRC-2 antibody (Fig. 5C). Western blot analysis of total lysates confirmed that c-Src and Fyn were expressed strongly in transfected cells and weakly in control (tau plus empty vector) cells (Fig. 5D).

However, Fyn is reported to phosphorylate tau primarily on Tyr-18 (Lee et al., 2004), raising the possibility that endogenous phosphorylation on Tyr-394 may be attributable to another kinase that is also sensitive to PP2. Although initially identified as high-potency inhibitors of Src tyrosine kinases (Hanke et al., 1996), PP1 and PP2 also inhibit the nonreceptor tyrosine kinase c-Abl with a similar potency (Liu et al., 1999; Tatton et al., 2003; Warmuth et al., 2003). In contrast, PP3, an analog of PP1 and PP2, has no effect on c-Abl activity (Traxler et al., 1997). Because 


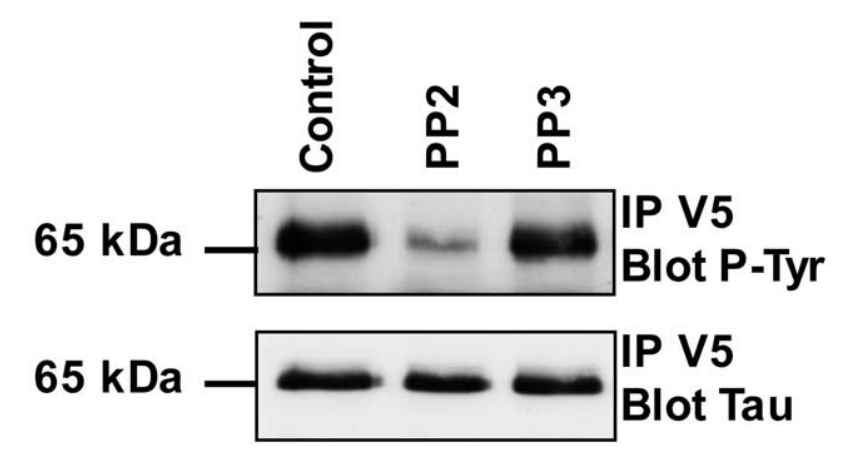

A

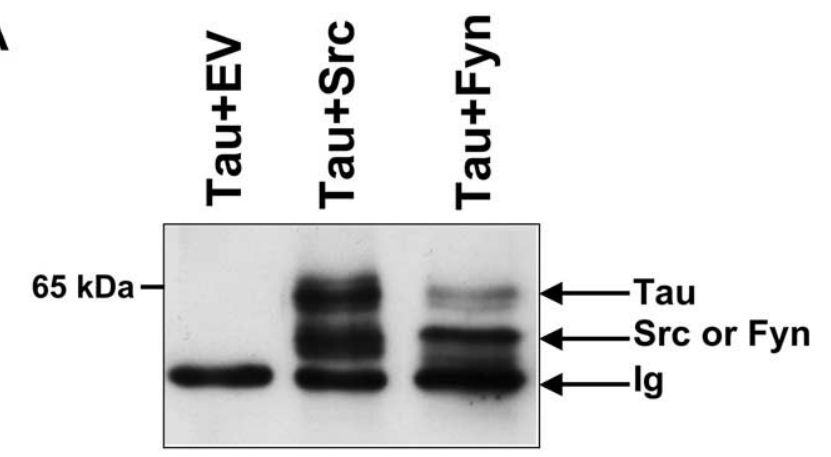

IP V5, Blot P-Tyr

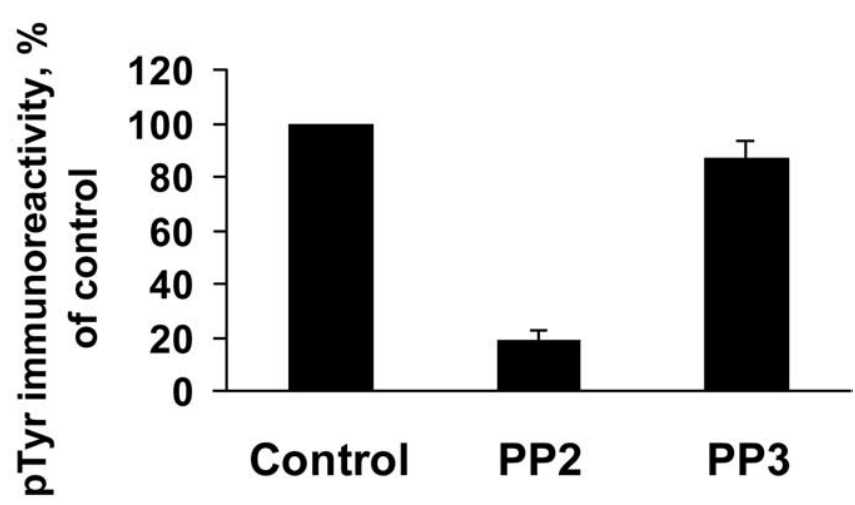

Figure 4. PP2, an Src family and c-Abl kinase inhibitor, prevents the pervanadate-induced tyrosine phosphorylation of tau. COS-7 cells were transiently transfected with V5-tagged tau and pretreated for $1 \mathrm{~h}$ with PP2 or PP3 and then treated with pervanadate for $20 \mathrm{~min}$, harvested, immunoprecipitated, and analyzed by Western blot analysis. Quantification was performed, and results show the mean values \pm SEM from four separate experiments.

c-Abl is expressed in both COS-7 and CHO cells (data not shown), this suggests that some of the effects of PP2 on the tyrosine phosphorylation of tau may be attributable to inhibition of c-Abl. c-Abl is expressed in the brain, where it plays a critical role in neuronal development (Koleske et al., 1998), and the sequence flanking Tyr-394 on tau (VYKSP) matches the optimal substrate sequence for c-Abl (I/VYXXP) (Wu et al., 2002; Obenauer et al., 2003).

Therefore, to determine whether c-Abl can phosphorylate tau in $\mathrm{CHO}$ cells, cotransfection experiments were performed using $\mathrm{c}-\mathrm{Abl}$ and $\mathrm{c}-\mathrm{Abl} \Delta \mathrm{XB}$ expression vectors. $\mathrm{c}-\mathrm{Abl} \Delta \mathrm{XB}$, a constitutively active mutant of $\mathrm{c}-\mathrm{Abl}$, was used because the basal kinase activity of $\mathrm{c}-\mathrm{Abl}$ is low. Both $\mathrm{c}-\mathrm{Abl}$ and $\mathrm{c}-\mathrm{Abl} \Delta \mathrm{XB}$, but not the empty vector, induce an increase in tau tyrosine phosphorylation when cotransfected with tau into $\mathrm{CHO}$ cells (Fig. 6A). As predicted, the increase of tau tyrosine phosphorylation was greater with c-Abl $\Delta \mathrm{XB}$ than with c-Abl. c-Abl could be phosphorylating tau directly or indirectly by acting through c-Abl-activated pathways involving other kinase(s). To help distinguish between these two possibilities, in vitro phosphorylation assays using purified $\mathrm{c}-\mathrm{Abl}$ and tau were performed. Tau was phosphorylated in vitro by c-Abl as judged on Western blots with 4G10, whereas no phosphorylation was observed in experiments in which tau was incubated without c-Abl (Fig. 6B). These results demonstrate that $\mathrm{c}-\mathrm{Abl}$ is indeed a tau kinase.

When Abl or Abl $\Delta \mathrm{XB}$ was cotransfected with tau, tau immunoprecipitates contained a $\sim 140 \mathrm{kDa}$ band, recognized by phosphotyrosine antibodies (data not shown). This band was sus-

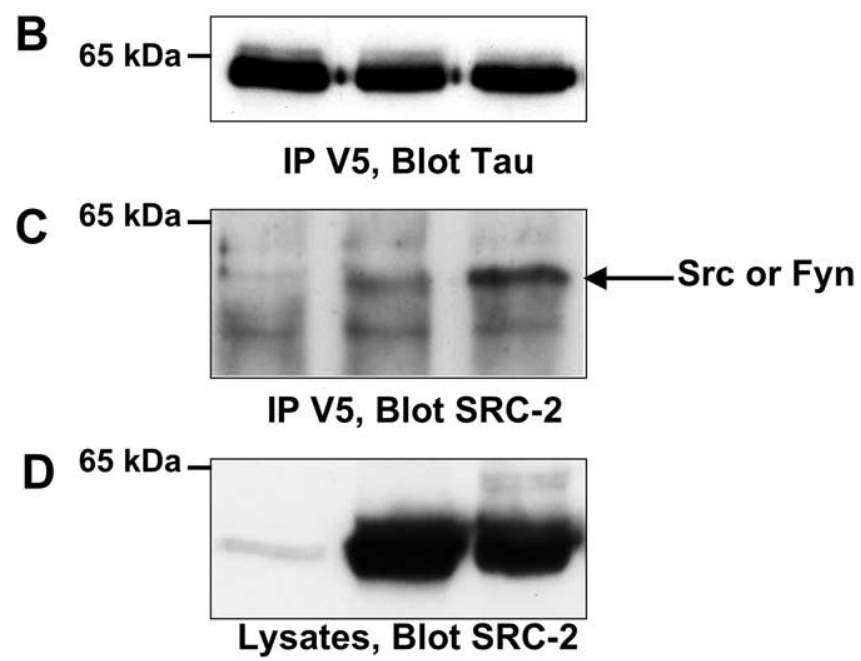

Figure 5. The Src family kinases, $c-S r c$ and Fyn, phosphorylate tau in transfected CHO cells. CHO cells were cotransfected with V5-tagged human tau and constructs expressing Src isolated by immunoprecipitation (IP V5); blots were probed in $A$ with 4G10 (IPV5, Blot P-Tyr), in $B$ with TP70 (IPV5, Blot Tau), and in (with the pan-Src antibody SRC-2 demonstrating that both Src and Fyn were coimmunoprecipitated with tau (IP V5, Blot SRC-2). D shows Western blots of cell lysates before immunoprecipitation to demonstrate transfection of the kinases using SRC-2 antibody.

pected to contain Abl or its truncated and activated form, because these enzymes are tyrosine phosphorylated. This was confirmed by blotting the tau immunoprecipitation with c-Abl antibodies (Fig. 6C), showing that c-Abl binds to tau.

\section{Tyrosine 394 is the primary residue in tau phosphorylated} by c-Abl

To map the tyrosine residue(s) phosphorylated by c-Abl and Fyn in tau, each kinase was cotransfected into $\mathrm{CHO}$ cells along with wild-type or mutant tau constructs in which individual tyrosines were replaced by phenylalanine.

As observed previously with pervanadate (Fig. $3 A$ ), when c-Abl $\Delta \mathrm{XB}$ was cotransfected with the Y394F mutant construct, there was a strong decrease in tyrosine phosphorylation compared with the wild-type construct (Fig. 7A). Cotransfection of c-Abl with Y197F or Y310F resulted in a moderate but reproducible decrease in tau tyrosine phosphorylation (Fig. 7A). In contrast, tyrosine phosphorylation of the Y18F and Y29F constructs was not significantly different from the wild-type control. This indicates that tyrosine 394 is the major tyrosine phosphorylation site in c-Abl-cotransfected cells. Cotransfection of Fyn with the same tau constructs gave strikingly different results: Y18F is the only single-tyrosine mutation that results in a significant effect, (Tau+Src), Fyn (Tau+Fyn), or empty vector (Tau+EV). Cells were harvested, and tau was 
reducing phosphotyrosine immunoreactivity to $\sim 20 \%$ of the wild-type control (Fig. 7B). Cotransfection of Fyn with Y310F, in two of the four experiments that were conducted, resulted in a decrease in tau phosphorylation. In contrast, tyrosine phosphorylation of the Y29F, Y197F, and Y394F constructs were not significantly different from the wild-type control. Together, these results show that c-Abl and Fyn phosphorylate different sites on tau: Tyr-18 is the major tyrosine phosphorylation site for Fyn, whereas Tyr-394 is the major site for c-Abl.

\section{$\mathrm{Abl}$ is induced and redistributed in pretangle neurons in Alzheimer's diseased brain}

When tissue sections from the hippocampus of $\mathrm{AD}$ or control brains were immunolabeled using anti-c-Abl antibody, the majority of cells showed only very weak and diffuse labeling. In $\mathrm{AD}$ cases, however, a population of neurons in the Ammon's horn of the hippocampus and in the adjacent temporal cortex showed a granular and faintly diffuse cytoplasmic Abl labeling. Dual labeling was performed using AT8, a monoclonal antibody that recognizes a phosphorylated epitope in PHF tau and stains classic NFT and also pretangle neurons that already have some tau pathology but not normal healthy neurons. The majority of cells showing diffuse Abl immunoreactivity were also AT8 positive, with granular and patchy tau-positive material, as seen in the early stages of tangle formation. Some neurons were stained more strongly with AT8, and this immunoreactivity partially colocalized with the Abl immunoreactivity (Fig. $8 A-C$ ). At least some of the Abl-positive granules (Fig. 8, arrowheads) corresponded to the central granules of granulovacuolar degeneration (GVD). Occasional GVD was also labeled in the control cases. In three AD cases examined, $6 \pm 1 \%$ (SEM) of the AT8positive neurons were also Abl positive. It seems that as NFTs develop in neurons, these cells are Abl positive, and the Abl is often enriched in cytoplasmic granules; however, in neurons that contain mature tangles, the $\mathrm{Abl}$ appears not to persist at elevated levels (Fig. 8D-F). Therefore, during NFT formation, Abl is redistributed and apparently elevated in at least some neurons, in which Abl and tau can show a considerable amount of colocalization (Fig. $8 \mathrm{~A}-\mathrm{C}$ ). This is consistent with $\mathrm{Abl}$ having a role in the development of tau pathology.

\section{Discussion}

We have identified by LC/MS/MS that Tyr-394 is phosphorylated in PHF tau from the AD brain and in human fetal brain tau. These results demonstrate that phosphorylation of tau on Tyr-394 is a physiological event, which could also be involved in the process leading to neurodegeneration in the tauopathies. Using two different antibodies that recognize phosphotyrosine 18, tau was shown to be phosphorylated on Tyr-18 in the fetal mouse brain as
B

C
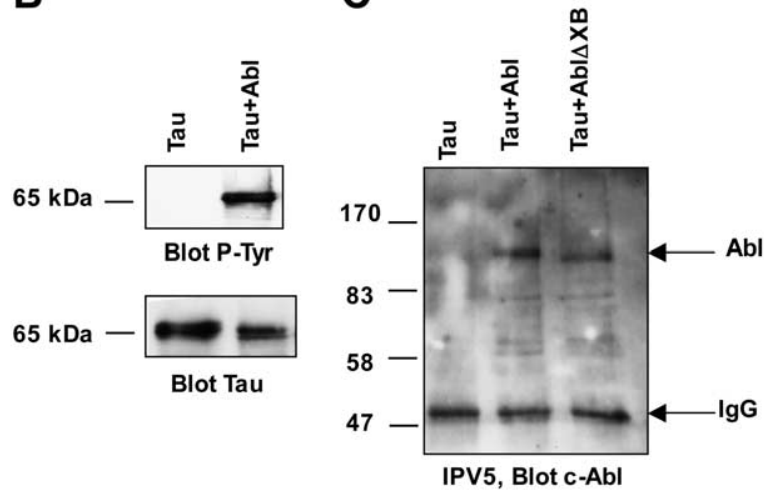

Figure 6. c-Abl phosphorylates tau in both transfected $\mathrm{CHO}$ cells and by direct in vitro phosphorylation. $\boldsymbol{A}, \mathrm{CHO}$ cells were reactions were analyzed by Western blotting using $8 \%$ gels and 4G10 (Blot PTyr) and TP70 (Blot Tau). C, Cells were transfected,

A

Figure 7. Tyr-394 is the major site phosphorylated in tau by c-Abl, whereas Tyr-18 is the primary site phosphorylated by Fyn in transfected $\mathrm{CHO}$ cells. Cells were cotransfected with constructs expressing c-Abl $\Delta \mathrm{XB}(\boldsymbol{A})$, Fyn $(\boldsymbol{B})$, or empty vector (EV) and with were probed as indicated, with 4G10 (Blot PTyr), TP70 (Blot Tau), c-Abl s.c.-23 (Blot Abl), c-Abl [pY ${ }^{412}$ ] (Blot Abl-PY), SRC-2 (Blot SRC-2), and Phospho-Src family, Tyr-416 (Blot Fyn-PY). The data presented are representative of three independent experiments.
B

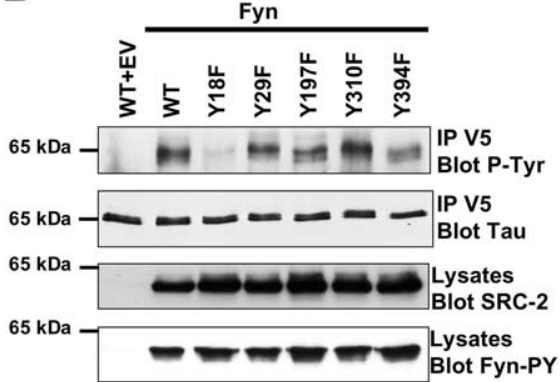

well as in PHF preparations and NFTs in situ (Lee et al., 2004), confirming the tyrosine phosphorylation of PHF tau we reported previously (Williamson et al., 2002). The sequence flanking Tyr394 in tau is highly conserved between mammalian species (human, rhesus monkey, rat, mouse, goat, and cow) (Nelson et al., 1996). In contrast, the region of tau containing Tyr-18 and Tyr-29 in the human and rhesus monkey is quite dissimilar to that in the other species that lack a stretch of 10 or 11 amino acids that includes one of these two tyrosines. Phosphorylation at Tyr18 , therefore, could have a role in the development of tauopathies, which seem to be a primarily human phenomenon. Equally, phosphorylation at Tyr-394 could also be involved in both physiological and pathological roles of tau, and thus it is important to identify the kinase or kinases that phosphorylate Tyr-394.

In the second part of the study, we determined whether Tyr394 is the main tyrosine residue phosphorylated in tau and which kinases are involved in tau tyrosine phosphorylation. Most cells exhibit low steady-state protein phosphotyrosine levels, reflecting the tight regulation of protein tyrosine kinase activity and the relatively high ratio of the activity of tyrosine phosphatases to tyrosine kinases (Girault, 1993; Hunter, 1995). Thus, to study tau 

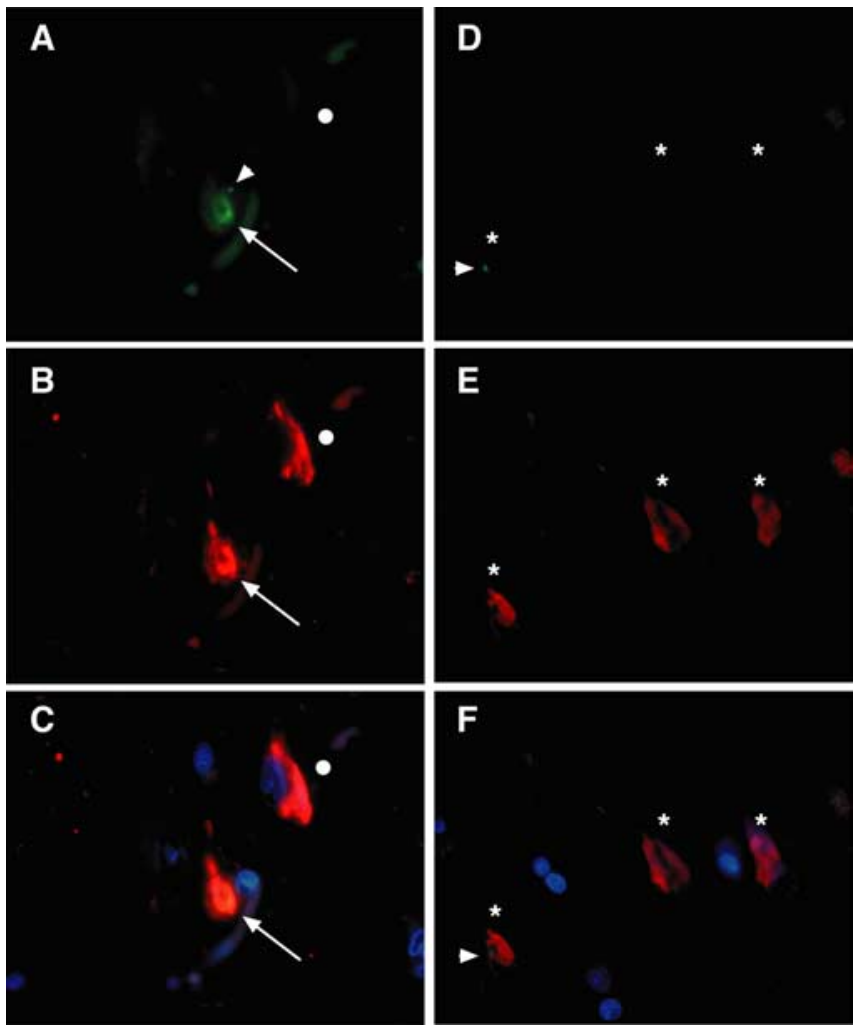

Figure 8. Immunofluorescence labeling of Abl in a subpopulation of NFT-containing neurons. Hippocampal sections from an $A D$ brain were labeled with anti-c-Abl antibody visualized with Alexa 488 green fluorophore $(\boldsymbol{A}, \boldsymbol{D})$ and with anti-phosphotau antibody AT8 visualized with Alexa 594 red fluorophore $(\boldsymbol{B}, \boldsymbol{E})$, followed by DAPI staining of nuclei. Merged images with DAPI staining are shown in $\boldsymbol{C}$ and $\boldsymbol{F}$. $\boldsymbol{A}$ - $\boldsymbol{C}$, An AT8-positive neuron (arrow) contains a tangle and also an Abl-positive granule ( $\boldsymbol{A}$, arrowhead). An adjacent neuron (white circle) has a strong AT8-positive tangle but gives only weak and diffuse Abl staining. $\boldsymbol{D}-\boldsymbol{F}$, Three neurons containing strongly AT8-positive NFT (asterisks), one of which contains an Abl-positive granule. At least 40 AT8-positive neurons were examined from each of three AD brains, and $6 \pm 1 \%$ (SEM) of these also stained positively for Abl.

tyrosine phosphorylation in cells, we used the protein tyrosine phosphatase inhibitor pervanadate in COS cells transfected with different tau constructs. The tyrosine phosphorylation of tau in response to pervanadate occurs primarily on Tyr-394 with little phosphorylation occurring on the other tyrosine residues. Also, in SHSY5Y neuroblastoma cells, the Y394F mutant showed a strong reduction in phosphorylation, suggesting that, here also, Tyr-394 is the main site for tyrosine phosphorylation. A recent report showed that Tyr-18 is the main tyrosine residue phosphorylated in tau when both tau and Fyn are cotransfected into COS cells (Lee et al., 2004). This apparent discrepancy suggested to us that tau might be phosphorylated by an endogenous kinase other than Fyn.

Treatment of cells with the tyrosine kinase inhibitor PP2 dramatically decreased the pervanadate-induced tyrosine phosphorylation of tau, suggesting that Src-family kinases could be involved in tau phosphorylation in cells (Hanke et al., 1996). Although PP2 was originally described as a specific inhibitor of the Src-family kinases, subsequent reports showed that PP2 and closely related compounds such as PP1 also inhibit the tyrosine kinase c-Abl (Liu et al., 1999; Tatton et al., 2003; Warmuth et al., 2003). Interestingly, the sequence flanking Tyr-394 does not match the consensus sequence for Src and Fyn (Songyang and Cantley, 1995; Dente et al., 1997) but resembles the known canonical substrate sequence determined for c-Abl (Songyang and Cantley, 1995; Dente et al., 1997; Wu et al., 2002; Obenauer et al.,
2003). This led us to investigate c-Abl as a candidate tau kinase. Cotransfection of $\mathrm{Abl}$ and tau resulted in highly preferential phosphorylation of tau on Tyr-394 in cells, and recombinant Abl was shown to phosphorylate recombinant tau in vitro.

The c-Abl family of nonreceptor tyrosine kinases consists of $\mathrm{c}-\mathrm{Abl}$ and its only paralog Arg. c-Abl is a ubiquitously expressed $140 \mathrm{kDa}$ protein, which is localized at several subcellular sites (for review, see Van Etten, 1999; Pendergast, 2002; Hantschel and Superti-Furga, 2004). c-Abl and Arg contain SH3 and SH2 domains in tandem and share C-terminal actin-binding domains that are not found in other tyrosine kinases. Through these domains, cytoplasmic c-Abl associates with F-actin bundles and focal adhesions (Van Etten et al., 1994). There is mounting evidence that Abl-family kinases play a key role in the development of the CNS. Mice lacking both c-Abl and Arg show neural tube defects (Koleske et al., 1998), and c-Abl promotes neurite extension in cortical neurons (Zukerberg et al., 2000; Woodring et al., 2002) and dendritogenesis in hippocampal neurons (Jones et al., 2004). The abl gene is conserved in invertebrates, and Drosophila Abl functions in axon guidance through binding to a multimolecular complex (Van Etten, 1999; Moresco and Koleske, 2003).

c-Abl is already medically important, because mutations of this kinase cause several leukemias in humans (Van Etten, 1992, 2004). Our finding of phosphorylation of Tyr-394 in PHF tau isolated from an $\mathrm{AD}$ brain suggests that excess tyrosine phosphorylation of tau may be involved in the development of Alzheimer pathology. Tyrosine-18 was also shown from immunological data to be phosphorylated in some NFTs (Lee et al., 2004). Treatment of hippocampal cells with fibrillar $\mathrm{A} \beta$ increased both the expression and activity of $\mathrm{c}-\mathrm{Abl}$ and also induced apoptosis (Alvarez et al., 2004). Inhibition of Abl activity with STI571 (4-[(4methyl-1-piperazinyl)methyl]-N-[4-methyl-3-[[4-(3-pyridinyl)-2yrimidinyl]amino]-phenyl]benzamide) protected hippocampal neurons from $\mathrm{A} \beta$-induced apoptosis, and suppression of $\mathrm{Abl}$ mRNA levels protected NR2a cells from $\mathrm{A} \beta$-induced toxicity (Alvarez et al., 2004). Interestingly, tau is essential for the neurotoxicity induced by A $\beta$ (Rapoport et al., 2002), and we reported previously that $A \beta$ induced the phosphorylation of tau on tyrosine (Williamson et al., 2002). Thus, it is tempting to speculate that the Abl-induced toxicity is mediated through the tyrosine phosphorylation of tau by $\mathrm{c}-\mathrm{Abl}$. This is strengthened by our finding that Abl distribution was altered in neurons from $\mathrm{AD}$ brain, with elevated amounts in some neurons, particularly pretangle neurons. This could be secondary to induction of c-Abl by $\mathrm{A} \beta$ or by oxidative products of local inflammation (Alvarez et al., 2004). Our demonstration of binding of tau to $\mathrm{c}-\mathrm{Abl}$ and $\mathrm{c}-\mathrm{Abl} \Delta \mathrm{XB}$ is consistent with tau being a specific substrate for $\mathrm{Abl}$ and for their involvement in a cell-signaling pathway. Unlike Src-family kinases, which interact with tau through their $\mathrm{SH} 3$ domains (Lee et al., 1998), c-Abl is likely to use a different mechanism. The SH3 domain of c-Abl is deleted partially in c-Abl $\Delta \mathrm{XB}$, yet this protein interacted with tau similarly to native c-Abl. Furthermore, the $\mathrm{SH} 3$ of Abl did not bind to tau (Lee et al., 1998).

The finding that $\mathrm{Abl}$ is elevated in neurons that are in the early stages of tangle formation raises the possibility that tyrosine phosphorylation may initiate or promote tau aggregation. Stress activation of c-Abl leads to various downstream effects, including activation of serine/threonine protein kinases (Van Etten, 1999). At least one of these, c-Jun N-terminal kinase, is a known tau kinase, which phosphorylates tau sites that are found to be phosphorylated in PHF (Goedert et al., 1997; Reynolds et al., 1997, 2000). Furthermore, another tau kinase, cdk5, which is thought to be important in the generation of tau pathology (Noble et al., 2003), can be phosphorylated and activated by c-Abl (Zukerberg 
et al., 2000). Therefore, as well as phosphorylating tau on tyrosine, c-Abl may promote pathological serine/threonine phosphorylation of tau. We were unsuccessful, however, in demonstrating changes in serine/threonine phosphorylation using phosphospecific antibodies (our unpublished observations). Additionally, Abl can be activated by Src-family kinases (e.g., in response to growth factors) (Plattner et al., 1999), and thus the two candidate kinases, $\mathrm{Abl}$ and Fyn, may act in concert in some situations.

It is also possible that phosphorylation of tau on Tyr-394 may promote its aggregation directly, but we have not been able to show increased aggregation in vitro of Abl-phosphorylated tau (our unpublished observations). An indirect mechanism as outlined above may therefore be more likely.

Our finding of elevated $\mathrm{Abl}$ in pretangle neurons rather than in neurons containing mature tangles suggests that the Tyr-394phosphorylated tau that we had identified by mass spectrometry may have originated predominantly from pretangle neurons. Studies are under way to develop phosphotyrosine-394-specific antibodies that will enable this prediction to be tested by immunolabeling.

However, we also found phosphorylated Tyr-394 in fetal brain tau, suggesting that this phosphorylation is a normal physiological event. We have not found evidence that tyrosine phosphorylation of tau affects binding to microtubules (our unpublished observations), and phosphorylation of Tyr-18 was also reported not to affect its binding to microtubules (Lee et al., 2004), suggesting that tyrosine phosphorylation of tau may influence other properties.

There is mounting evidence that tau plays a role in cell signaling. Tau can interact with various signaling molecules, including PLC- $\gamma$ (Hwang et al., 1996; Jenkins and Johnson, 1998), Srcfamily kinases (Lee et al., 1998), and protein phosphatases 1 (Liao et al., 1998) and 2A (Sontag et al., 1999; Eidenmuller et al., 2001). Moreover, tau and catalytically active Fyn are both required for oligodendrocyte outgrowth (Klein et al., 2002). Any such signaling role of tau may be distinct from its actions on microtubules. Indeed, a proportion of tau in cells is bound to membranes (Brandt et al., 1995; Maas et al., 2000). The results presented here suggest that $\mathrm{c}-\mathrm{Abl}$ is both a tau kinase and a binding partner.

In conclusion, our findings significantly contribute to the understanding of the signaling pathways involving tyrosine phosphorylation of tau in both physiological and pathological conditions. Additional elucidation of the functional relationship between tau and the Abl family of tyrosine kinases in neurons could provide critical insights into the role of tau in cell signaling and development as well as in neurodegenerative processes.

\section{References}

Alvarez AR, Sandoval PC, Leal NR, Castro PU, Kosik KS (2004) Activation of the neuronal c-Abl tyrosine kinase by amyloid-beta-peptide and reactive oxygen species. Neurobiol Dis 17:326-336.

Anderton BH, Betts J, Blackstock WP, Brion JP, Chapman S, Connell J, Dayanandan R, Gallo JM, Gibb G, Hanger DP, Hutton M, Kardalinou E, Leroy K, Lovestone S, Mack T, Reynolds CH, Van Slegtenhorst M (2001) Sites of phosphorylation in tau and factors affecting their regulation. Biochem Soc Symp 67:73-80.

Betts JC, Blackstock WP, Ward MA, Anderton BH (1997) Identification of phosphorylation sites on neurofilament proteins by nanoelectrospray mass spectrometry. J Biol Chem 272:12922-12927.

Biernat J, Gustke N, Drewes G, Mandelkow E-M, Mandelkow E (1993) Phosphorylation of Ser ${ }^{262}$ strongly reduces binding of tau to microtubules: distinction between PHF-like immunoreactivity and microtubule binding. Neuron 11:153-163.

Brandt R, Léger J, Lee G (1995) Interaction of tau with the neural plasma membrane mediated by tau's amino-terminal projection domain. J Cell Biol 131:1327-1340.

Brion J-P, Couck A-M, Robertson J, Loviny TLF, Anderton BH (1993) Neurofilament monoclonal antibodies RT97 and 8D8 recognize different modified epitopes in paired helical filament- $\tau$ in Alzheimer's disease. J Neurochem 60:1372-1382.

Buée L, Bussière T, Buée-Scherrer V, Delacourte A, Hof PR (2000) Tau protein isoforms, phosphorylation and role in neurodegenerative disorders. Brain Res Rev 33:95-130.

Daley GQ, Van Etten RA, Jackson PK, Bernards A, Baltimore D (1992) Nonmyristoylated Abl proteins transform a factor-dependent hematopoietic cell line. Mol Cell Biol 12:1864-1871.

Delacourte A, Buée L (2000) Tau pathology: a marker of neurodegenerative disorders. Curr Opin Neurol 371-376.

Dente L, Vetriani C, Zucconi A, Pelicci G, Lanfrancone L, Pelicci PG, Cesareni G (1997) Modified phage peptide libraries as a tool to study specificity of phosphorylation and recognition of tyrosine containing peptides. J Mol Biol 269:694-703.

Derkinderen P, Girault JA (1997) Protein tyrosine phosphorylation. In: Post translational modifications: techniques and methods. (Boulton AA, Baker GB, Hemmings HC, eds), pp 251-274. Totowa, NJ: Humana.

Eidenmuller J, Fath T, Maas T, Pool M, Sontag E, Brandt R (2001) Phosphorylation-mimicking glutamate clusters in the proline-rich region are sufficient to simulate the functional deficiencies of hyperphosphorylated tau protein. Biochem J 357:759-767.

Girault J-A (1993) Protein phosphorylation and dephosphorylation in mammalian central nervous system. Neurochem Int 23:1-25.

Goedert M, Hasegawa M, Jakes R, Lawler S, Cuenda A, Cohen P (1997) Phosphorylation of microtubule-associated protein tau by stress- activated protein kinases. FEBS Lett 409:57-62.

Gordon JA (1991) Use of vanadate as protein-phosphotyrosine phosphatase inhibitor. Methods Enzymol 201:477-482.

Hanger DP, Betts JC, Loviny TLF, Blackstock WP, Anderton BH (1998) New phosphorylation sites identified in hyperphosphorylated tau (paired helical filament-tau) from Alzheimer's disease brain using nanoelectrospray mass spectrometry. J Neurochem 71:2465-2476.

Hanke JH, Gardner JP, Dow RL, Changelian PS, Brissette WH, Weringer EJ, Pollok K, Connelly PA (1996) Discovery of a novel, potent, and Src family-selective tyrosine kinase inhibitor-study of Lck- and FynTdependent T cell activation. J Biol Chem 271:695-701.

Hantschel O, Superti-Furga G (2004) Regulation of the c-Abl and Bcr-Abl tyrosine kinases. Nat Rev Mol Cell Biol 5:33-44.

Hunter T (1995) Protein kinases and phosphatases: the yin and yang of protein phosphorylation and signaling. Cell 80:225-236.

Hutton M, Lendon CL, Rizzu P, Baker M, Froelich S, Houlden H, PickeringBrown S, Chakraverty S, Isaacs A, Grover A, Hackett J, Adamson J, Lincoln S, Dickson D, Davies P, Petersen RC, Stevens M, De Graaff E, Wauters E, Van Baren J, et al. (1998) Association of missense and 5' -splicesite mutations in tau with the inherited dementia FTDP-17. Nature 393:702-705.

Huyer G, Liu S, Kelly J, Moffat J, Payette P, Kennedy B, Tsaprailis G, Gresser MJ, Ramachandran C (1997) Mechanism of inhibition of proteintyrosine phosphatases by vanadate and pervanadate. J Biol Chem 272:843-851.

Hwang SC, Jhon DY, Bae YS, Kim JH, Rhee SG (1996) Activation of phospholipase C-gamma by the concerted action of tau proteins and arachidonic acid. J Biol Chem 271:18342-18349.

Jackson P, Baltimore D (1989) N-terminal mutations activate the leukemogenic potential of the myristoylated form of c-abl. EMBO J 8:449-456.

Jenkins SM, Johnson GVW (1998) Tau complexes with phospholipase C-gamma in situ. NeuroReport 9:67-71.

Jones SB, Lu HY, Lu Q (2004) Abl tyrosine kinase promotes dendrogenesis by inducing actin cytoskeletal rearrangements in cooperation with $\rho$ family small GTPases in hippocampal neurons. J Neurosci 24:8510-8521.

Klein C, Kramer EM, Cardine AM, Schraven B, Brandt R, Trotter J (2002) Process outgrowth of oligodendrocytes is promoted by interaction of fyn kinase with the cytoskeletal protein tau. J Neurosci 22:698-707.

Koleske AJ, Gifford AM, Scott ML, Nee M, Bronson RT, Miczek KA, Baltimore D (1998) Essential roles for the Abl and Arg tyrosine kinases in neurulation. Neuron 21:1259-1272.

Laemmli UK (1970) Cleavage of structural proteins during the assembly of the head of bacteriophage T4. Nature 227:680-685. 
Lee G, Newman ST, Gard DL, Band H, Panchamoorthy G (1998) Tau interacts with src-family non-receptor tyrosine kinases. J Cell Sci 111:3167-3177.

Lee G, Thangavel R, Sharma VM, Litersky JM, Bhaskar K, Fang SM, Do LH, Andreadis A, Van Hoesen G, Ksiezak-Reding H (2004) Phosphorylation of tau by fyn: implications for Alzheimer's disease. J Neurosci 24:2304-2312.

Leroy K, Boutajangout A, Authelet M, Woodgett JR, Anderton BH, Brion JP (2002) The active form of glycogen synthase kinase-3beta is associated with granulovacuolar degeneration in neurons in Alzheimer's disease. Acta Neuropathol (Berl) 103:91-99.

Liao H, Li YR, Brautigan DL, Gundersen GG (1998) Protein phosphatase 1 is targeted to microtubules by the microtubule-associated protein Tau. J Biol Chem 273:21901-21908.

Liu Y, Bishop A, Witucki L, Kraybill B, Shimizu E, Tsien J, Ubersax J, Blethrow J, Morgan DO, Shokat KM (1999) Structural basis for selective inhibition of Src family kinases by PP1. Chem Biol 6:671-678.

Lovestone S, Reynolds CH (1997) The phosphorylation of tau: a critical stage in neurodevelopment and neurodegenerative processes. Neuroscience 78:309-324.

Lucas JJ, Hernandez F, Gomez-Ramos P, Moran MA, Hen R, Avila J (2001) Decreased nuclear beta-catenin, tau hyperphosphorylation and neurodegeneration in GSK-3beta conditional transgenic mice. EMBO J 20:27-39.

Maas T, Eidenmüller J, Brandt R (2000) Interaction of tau with the neural membrane cortex is regulated by phosphorylation at sites that are modified in paired helical filaments. J Biol Chem 275:15733-15740.

Maccioni RB, Otth C, Concha II, Muñoz JP (2001) The protein kinase Cdk5-structural aspects, roles in neurogenesis and involvement in Alzheimer's pathology. Eur J Biochem 268:1518-1527.

Moresco EM, Koleske AJ (2003) Regulation of neuronal morphogenesis and synaptic function by Abl family kinases. Curr Opin Neurobiol 13:535-544.

Morishima-Kawashima M, Hasegawa M, Takio K, Suzuki M, Yoshida H, Titani K, Ihara Y (1995) Proline-directed and non-proline-directed phosphorylation of PHF-tau. J Biol Chem 270:823-829.

Mulot SFC, Hughes K, Woodgett JR, Anderton BH, Hanger DP (1994) PHF-tau from Alzheimer's brain comprises four species on SDS-PAGE which can be mimicked by in vitro phosphorylation of human brain tau by glycogen synthase kinase-3 $\beta$. FEBS Lett 349:359-364.

Nelson PT, Stefansson K, Gulcher J, Saper CB (1996) Molecular evolution of $\tau$ protein: implications for Alzheimer's disease. J Neurochem 67:1622-1632.

Noble W, Olm V, Takata K, Casey E, Mary O, Meyerson J, Gaynor K, LaFrancois J, Wang L, Kondo T, Davies P, Burns M, Veeranna, Nixon R, Dickson D, Matsuoka Y, Ahlijanian M, Lau LF, Duff K (2003) Cdk5 is a key factor in tau aggregation and tangle formation in vivo. Neuron 38:555-565.

Obenauer JC, Cantley LC, Yaffe MB (2003) Scansite 2.0: proteome-wide prediction of cell signaling interactions using short sequence motifs. Nucleic Acids Res 31:3635-3641.

Pendergast AM (2002) The Abl family kinases: mechanisms of regulation and signaling. Adv Cancer Res 85:51-100.

Plattner R, Kadlec L, DeMali KA, Kazlauskas A, Pendergast AM (1999) $\mathrm{c}$-Abl is activated by growth factors and Src family kinases and has a role in the cellular response to PDGF. Genes Dev 13:2400-2411.

Poorkaj P, Bird TD, Wijsman E, Nemens E, Garruto RM, Anderson L, Andreadis A, Wiederholt WC, Raskind M, Schellenberg GD (1998) Tau is a candidate gene for chromosome 17 frontotemporal dementia. Ann Neurol 43:815-825.

Rapoport M, Dawson HN, Binder LI, Vitek MP, Ferreira A (2002) Tau is essential to beta-amyloid-induced neurotoxicity. Proc Natl Acad Sci USA 99:6364-6369.

Reynolds CH, Utton MA, Gibb GM, Yates A, Anderton BH (1997) Stressactivated protein kinase/c-Jun N-terminal kinase phosphorylates $\tau$ protein. J Neurochem 68:1736-1744.

Reynolds CH, Betts JC, Blackstock WP, Nebreda AR, Anderton BH (2000) Phosphorylation sites on tau identified by nanoelectrospray mass spec- trometry: differences in vitro between the mitogen-activated protein kinases ERK2, c-Jun N-terminal kinase and P38, and glycogen synthase kinase-3 $\beta$. J Neurochem 74:1587-1595.

Roepstorff P, Fohlman J (1984) Proposal for a common nomenclature for sequence ions in mass spectra of peptides. Biomed Mass Spectrom 11:601.

Shevchenko A, Chernushevic I, Shevchenko A, Wilm M, Mann M (2002) "De novo" sequencing of peptides recovered from in-gel digested proteins by nanoelectrospray tandem mass spectrometry. Mol Biotechnol 20:107-118.

Smith C, Anderton BH (1994) Dorothy Russell memorial lecture. The molecular pathology of Alzheimer's disease: are we any closer to understanding the neurodegenerative process? Neuropathol Appl Neurobiol 20:322-338.

Songyang Z, Cantley LC (1995) Recognition and specificity in protein tyrosine kinase-mediated signalling. Trends Biochem Sci 20:470-475.

Sontag E, Nunbhakdi-Craig V, Lee G, Brandt R, Kamibayashi C, Kuret J, White III CL, Mumby MC, Bloom GS (1999) Molecular interactions among protein phosphatase $2 \mathrm{~A}$, tau, and microtubules-implications for the regulation of tau phosphorylation and the development of tauopathies. J Biol Chem 274:25490-25498.

Spillantini MG, Goedert M (1998) Tau protein pathology in neurodegenerative diseases. Trends Neurosci 21:428-433.

Spittaels K, Van Den Haute C, Van Dorpe J, Geerts H, Mercken M, Bruynseels K, Lasrado R, Vandezande K, Laenen I, Boon T, Van Lint J, Vandenheede J, Moechars D, Loos R, Van Leuven F (2000) Glycogen synthase kinase- $3 \beta$ phosphorylates protein tau and rescues the axonopathy in the central nervous system of human four-repeat tau transgenic mice. J Biol Chem 275:41340-41349.

Tatton L, Morley GM, Chopra R, Khwaja A (2003) The Src-selective kinase inhibitor PP1 also inhibits Kit and Bcr-Abl tyrosine kinases. J Biol Chem 278:4847-4853.

Traxler P, Bold G, Frei J, Lang M, Lydon N, Mett H, Buchdunger E, Meyer T, Mueller M, Furet P (1997) Use of a pharmacophore model for the design of EGF-R tyrosine kinase inhibitors: 4-(phenylamino)pyrazolo[3,4d]pyrimidines. J Med Chem 40:3601-3616.

Van Etten RA (1992) Malignant transformation by abl and BCR/ABL. Cancer Treat Res 63:167-192.

Van Etten RA (1999) Cycling, stressed-out and nervous: cellular functions of c-Abl. Trends Cell Biol 9:179-186.

Van Etten RA (2004) Mechanisms of transformation by the BCR-ABL oncogene: new perspectives in the post-imatinib era. Leuk Res 28 [Suppl 1]:S21-S28.

Van Etten RA, Jackson PK, Baltimore D, Sanders MC, Matsudaira PT, Janmey PA (1994) The COOH terminus of the c-Abl tyrosine kinase contains distinct F- and $\mathrm{G}$-actin binding domains with bundling activity. J Cell Biol 124:325-340.

Warmuth M, Simon N, Mitina O, Mathes R, Fabbro D, Manley PW, Buchdunger E, Forster K, Moarefi I, Hallek M (2003) Dual-specific Src and Abl kinase inhibitors, PP1 and CGP76030, inhibit growth and survival of cells expressing imatinib mesylate-resistant Bcr-Abl kinases. Blood 101:664-672.

Williamson R, Scales T, Clark BR, Gibb G, Reynolds CH, Kellie S, Bird IN, Varndell IM, Sheppard PW, Everall I, Anderton BH (2002) Rapid tyrosine phosphorylation of neuronal proteins including tau and focal adhesion kinase in response to amyloid- $\beta$ peptide exposure: involvement of Src family protein kinases. J Neurosci 22:10-20.

Woodring PJ, Litwack ED, O’Leary DD, Lucero GR, Wang JY, Hunter T (2002) Modulation of the F-actin cytoskeleton by c-Abl tyrosine kinase in cell spreading and neurite extension. J Cell Biol 156:879-892.

Wu JJ, Afar DE, Phan H, Witte ON, Lam KS (2002) Recognition of multiple substrate motifs by the c-ABL protein tyrosine kinase. Comb Chem High Throughput Screen 5:83-91.

Zukerberg LR, Patrick GN, Nikolic M, Humbert S, Wu CL, Lanier LM, Gertler FB, Vidal M, Van Etten RA, Tsai LH (2000) Cables links Cdk5 and $\mathrm{c}-\mathrm{Abl}$ and facilitates Cdk5 tyrosine phosphorylation, kinase upregulation, and neurite outgrowth. Neuron 26:633-646. 